\title{
Guiding Strategy of Local Government to Capital under the Background of Integration Innovation

\author{
Xiao Sun
}

School of Government Beijing Normal University, Beijing China

Email: 418470072@qq.com

Keywords: Integration innovation; Local government; Capital; Guiding strategy

\begin{abstract}
Through a long process of development, the current innovation is more advocating integration of innovation. The integration innovation emphasizes the organic interaction between the innovation subject and the beneficiaries of innovation. The key factor on capital is government's guidance, which is to realize the organic interaction between the innovation subject and the innovation beneficiaries. The essay puts forward the local government to guide the capital strategy to ensure that the Government to give full play to the role of the first action group to promote the rational use of capital from the economic capital, cultural capital and social capital perspective combined with the classic capital classification.
\end{abstract}

\section{Introduction}

Integration Innovation. The early Western innovation theory has experienced a long process of development from the beginning of the early linear innovation and emphasizing the theoretical knowledge for the practical application of the promotion to the gradual display of non-linear characteristics of innovation rooted in emerging market demand. And then it tends to be the frugal innovation, system innovation, open innovation and innovative network thinking. In recent years, it puts forward a new concept of integration innovation. Through the use of modular integration strategy, combining technological innovation with social innovation, using interdisciplinary cross-sector approach to seek innovating the Complexity Challenge Solution in Innovation Activities, integration innovation is a combination of different subjects such as government, enterprise, scientific research institutions, social organizations and so on. There are three most significant features of integration innovation: first, integration of innovative goals; second, integration of innovation and income; third, interdisciplinary research methods integration. Among them, the second point is most important. Integration innovation emphasizes the organic interaction of innovative beneficiaries of innovation. Institutions of higher learning, government, private enterprises, investors, consumers can be the main body of innovation. But the government as a master of resources no doubt occupied an important part in all the main body.

Capital Classification. Capital can be divided into three categories by the division of Bourdieu' book The Form of Capital. The first is the economic capital, the second is the cultural capital and the third is the social capital as shown in Table 1.

Table 1 Bourdieu Capital classification list

\begin{tabular}{|c|c|c|}
\hline Capital Type & Media and Symbol & Institutionalized Form \\
\hline Economic Captal & Money & Property Rights \\
\hline Cutural Capital & Diploma, Education, Certificate & Degrees \\
\hline Scocial Capital & $\begin{array}{c}\text { Social prestige, Reputation, } \\
\text { Authority and Title }\end{array}$ & Social Contracts \\
\hline
\end{tabular}

\section{Local Government Guidance of Economic Capital}

Increase Financial Support Efforts. Firstly, the government subsidizes the main innovation 
directly. A direct subsidy is a kind of pre-competitive behavior, whose nature is similar to price subsidies or government purchases in some respects. The government's direct subsidy is a very common act. Secondly, use the implementation of price returns. The return on the price is a kind of time when the direct subsidy is a subsidy, thus greatly reducing the risk of government subsidies and becoming an effective incentive for the innovation. Thirdly, use the implementation of consumption and production subsidies. The government subsidizes the main innovation, import tariff subsidies and loan guarantees directly. Fourthly, improve the tax subsidy system. The government uses implementation of tax credits from the taxable income of the cost of deduction of depreciation and amortization fees, which means the implementation of differential rates, tax rebates, or carries forward the system. However, tax subsidies as an innovative ex post incentive system only rely on output. According to the survey, for small and medium enterprises, its efficiency is far lower than the direct subsidies beforehand. Fifthly, use the implementation of government subsidies. Sixthly, the governments introduce foreign aid appropriately. For the time being, foreign aid is not the best way to inspire innovation, which is only a way to supplement innovative funds. Excessive foreign aid will lead to the purchase of $\mathrm{R} \& \mathrm{D}$ prices relative to the capital increase, and then lead to trade flows, change their own comparative advantage products.

The above six methods are for governments to increase the way of innovation and financial subsidies. However, when the governments put them into practice, two issues should be considered. The first one is that the choice of government financial subsidies depends on the extent to which the output of innovation can be reliably predicted and the effectiveness of the output. The second one is that the efficiency comparison. The government should compare the efficiency of investment in schools, nonprofit organizations and private enterprises in the use of innovative funds. The government's subsidy efficiency for capital is subject to further analysis and measurement by professional bodies.

Implementation of Governments Procurement. Government procurement is also a way to promote integration and innovation. Government procurement depends on the procurement contract, which has two natures to promote and to pull. In the push-type contract, the governments can provide the technical explanation and the foresight of the market to inspire the enterprise to enter the risky new innovation market. At the same time, the governments can also pull in the contract on behalf of the public's willingness to buy and promote business innovation.

However, government procurement is extremely easy to squeeze out private investment in the investment market. Under the era of integration and innovation, the governments should pay attention to the procurement areas in the market by focusing on innovation and return uncertainty of private enterprises, institutions, non-profit organizations and other fields. At the same time, pay attention to the diversification of government procurement channels, the implementation of supervision and management of procurement.

\section{Local Government Guidance of Cultural Capital}

Colleges and universities as the cultural capital concentration, the local government should strengthen the guidance of cultural capital by focusing on improving the enthusiasm of university personnel training, implement educational reform and striving to cultivate innovative talents. Similarly, as the main body and beneficiaries of innovative network relations, institutions of higher learning, government, investors and consumers should establish a more powerful social capital network and set up a clear path of a communication platform to promote the combination of industry and academia. Firstly, build a communication platform. The intrinsic relationship between investors and consumers determines their network ties. But the relationship between consumers and institutions of higher learning, government and institutions of higher learning, government and investors, investors and institutions of higher learning is not close enough, which requires the government to take the lead to build a communication platform network. Secondly, promote the combination of industry and academia. To promote the combination of industry and education, especially to strengthen the innovation cooperation between small and medium-sized enterprises and local colleges and universities, innovation cooperation is a cooperative concept of 
cross-organization cooperation. Professor Fu Jiawei holds the view that cooperation innovation is between enterprises, research institutions, institutions Joint innovation behavior. Cooperative innovation is usually based on the common interests of partners with resource sharing or complementary advantages as a prerequisite, a clear goal of cooperation, cooperation and cooperation rules, cooperation in the whole process of technological innovation or some common investment, common Participate in, share the results, share the risk. This requires the governments promote the cultural capital of the guide according to the law of cultural capital from the supply side, the demand side and the environment side, whose relationship among the three is shown in Fig. 1.

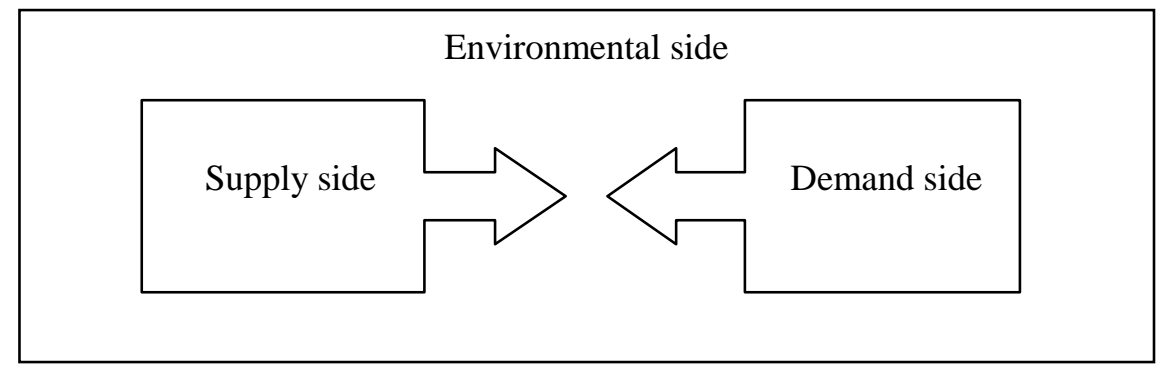

Figure 1. Diagram of Supply side, Demand side, Environment side

Policy tools of supply side. The tools contain enriching the university talent training mode, playing the role of innovation source; promoting the construction of innovative universities, encouraging faculty and workers knowledge innovation and entrepreneurship; improving the scientific and technological management of colleges and universities, increasing cooperation and innovation performance evaluation; establishing a platform for production and cooperation information; establishment of production and innovation platform for public innovation and accelerating the process of cooperation and innovation.

Policy tools of demand side. The governments should support for small and medium enterprises and local colleges and universities cooperation and innovation in the government purchase, public construction, business-oriented policy, military industrial policy and the buyer's credit policy.

Policy tools of environment side. The governments should provide small and medium enterprises and local colleges and universities cooperation and innovation activities required funds to improve the social financing channels and systems; provide tax and other preferential policies; strengthen intellectual property protection by early introduction of "cooperation law" and ensure the stability of the political environment, economic society Institutional predictability and so on.

\section{Local Government Guidance of social capital}

Social capital which does integrate the greatest potential in innovation is often overlooked by local governments. According to the definition of Bourdieu, social capital is a relatively stable, institutionalized and sustainable network of social relations, which can provide some resources.

Popular interpretation for social capital is the use of social relations network through mutual assistance, sharing and other forms to get access to resources. It exists in kinship, professional relations, organizational relations and neighborhood relations, etc., and is protected and strengthened through institutionalized network relations and immobilization of behavior.

Throughout the course of the development of social capital, the viewpoints of the scholars can be summarized as five categories of functional theory, interaction theory; normative theory, network theory and resource theory despite scholars have reached a consensus on social capital in three areas under the social-centered social capital and differences in individual-centered social capital. Firstly, they take the social capital as a resource, which shares the same position as physical capital. Secondly, the social capital attributes of productive and non-transferable understanding of the basic agreement (public property debate attributes on the public center-basis and personal center-basis).Thirdly, factors such as trust, relationships, networks, and norms are recognized by 
scholars as a major component of social capital, as well as in the context of socialism.

The government's guidance on social capital involves many aspects such as state governance, government governance and social governance.

At the leadership level, state governance, government governance and social governance are all the ruling activities carried out by the Communist Party of China under the premise of establishing and consolidating the fundamental system and basic system of the socialist system. They are the actual manifestations of the ruling position and ruling behavior of the Communist Party of China. In the overall situation of the Communist Party of China, it is to coordinate the overall pattern of the parties to run the power of the activities.

At the legal level, the rule of law is the basic strategy of the Chinese Communist Party to govern the country, which is the practical way to realize the party's leadership and the people's democracy and the rule of law. Therefore, it is also the basic follow-up of state governance, government governance and social governance. Construction of the rule of law China requires the rule of law to run the power of governance which means the government must manage and promote the state by adhering to the rule of law and the rule of law society. Obviously, these rules are relatively direct to correspond to the state governance, government governance and social governance clearly shows a variety of governance to follow the basic strategy.

At the institutional level, the objectives of state governance, government governance and social governance all point to the fact that we can get rid of all the institutional mechanisms which do not meet the requirements of the development of productive forces and innovate the institutional mechanisms for the release of productive forces and social vitality under the premise of upholding the fundamental and basic system of socialism with Chinese characteristics in order to perfect and develop the socialist system with Chinese characteristics.

\section{Acknowledgements}

Project support for the innovation project of Beijing Normal University.

\section{Reference}

[1] X.P. Tan, Z.H. Jiang. Cultural development of new power: culture and science and technology integration innovation [J]. Social Science and Technology, 2013, (07): 104-108.

[2] W. Wei. School-enterprise integration and innovation of higher vocational education philosophy and management model [J]. China Higher Education, 2006, (08): 47-49.

[3] W.G. Zhang, D. Chen, C. Wang. Regional Model and Upgrade Path of Foreign Investment R \& $\mathrm{D}$ and Regional Independent Innovation in China [J] .New Vision, 2014 (06): 36-40.

[4] W.G. Zhang, J. Lu, Laurette Dubé. Fusion innovation and its significance to China's innovation-driven development [J] Management of the world, 2016, (06): 1-9.

[5] J. Wu, J.Z. Xia. Foreign social capital theory: historical context and cutting-edge dynamics [J]. Academic circles, 2012 (08): 264-268.

[6] H. Zhang, S.Z. Wang. Social governance transformation and petition legalization reform [J]. Law World, 2016, (09): 34-42.

[7] Z.F. Tan. Innovative social governance and new political relations in the local government's multiple roles [J]. China Administration, 2016, (03): 77-80.

[8] C.Z. Wu, L. Zhang and J. Wang. Effects of Government Talent Policy on Regional Human Capital Stock [J] Cooperative Economy and Technology, 2014, (09): 52.

[9] Y. Li. Cultural capital, cultural diversity and social network capital [J] Sociology, 2001, (04): 52-63.

[10]L.P. Qiu, R.K Xiao. Cultural Capital and Social Status Acquisition - An Empirical Study Based on Shanghai [J] .Chinese Journal of Social Sciences, 2011, (06): 121-135. [J] Journal of Social Sciences, 2011, (06): 121-135. 